\title{
Influence of Battery Parametric Uncertainties on the State-of-Charge Estimation of Lithium Titanate Oxide-Based Batteries
}

\author{
Ana-Irina Stroe ${ }^{1, *}$, Jinhao Meng ${ }^{1,2}$, Daniel-Ioan Stroe ${ }^{1}$ (D), Maciej Świerczyński ${ }^{1}$, \\ Remus Teodorescu ${ }^{1}$ (iD) and Søren Knudsen Kær ${ }^{1}$ \\ 1 Department of Energy, Aalborg University, 9220 Aalborg, Denmark; jin@et.aau.dk (J.M.); \\ dis@et.aau.dk (D.-I.S.); mas@et.aau.dk (M.Ś.); ret@et.aau.dk (R.T.); skk@et.aau.dk (S.K.K.) \\ 2 School of Automation, Northwestern Polytechnical University, 710072 Xi'an, China \\ * Correspondence: irina22st@yahoo.com
}

Received: 21 February 2018; Accepted: 27 March 2018; Published: 30 March 2018

\begin{abstract}
State of charge (SOC) is one of the most important parameters in battery management systems, as it indicates the available battery capacity at every moment. There are numerous battery model-based methods used for SOC estimation, the accuracy of which depends on the accuracy of the model considered to describe the battery dynamics. The SOC estimation method proposed in this paper is based on an Extended Kalman Filter (EKF) and nonlinear battery model which was parameterized using extended laboratory tests performed on several 13 Ah lithium titanate oxide (LTO)-based lithium-ion batteries. The developed SOC estimation algorithm was successfully verified for a step discharge profile at five different temperatures and considering various initial SOC initialization values, showing a maximum SOC estimation error of $1.16 \%$ and a maximum voltage estimation error of $44 \mathrm{mV}$. Furthermore, by carrying out a sensitivity analysis it was showed that the SOC and voltage estimation error are only slightly dependent on the variation of the battery model parameters with the SOC.
\end{abstract}

Keywords: lithium-ion batteries; lithium titanate oxide (LTO) batteries; hybrid pulse power characterization test; model parameterization; equivalent electrical circuit; state of charge (SOC); extended Kalman filter

\section{Introduction}

Lithium-ion (Li-ion) batteries have developed as the key energy storage technology for automotive applications and are also evaluated in different stationary renewable energy storage applications [1-5]. This is mainly because Li-ion batteries are characterized by superior performance in terms of power capability, efficiency, lifetime than other storage technologies [2,6]. Moreover, in the past years, the price of Li-ion batteries has been decreasing faster than expected. However, Li-ion batteries are sensitive to overcharging and overdischarging. Thus, an accurate estimation of the battery state-of-charge (SOC), which will avoid the overcharging and overdischarging operation, is a very important feature of the battery management systems (BMS) [7]. In the case of a wrong SOC estimation, significant damage in the battery may occur and ultimately the lifetime of the battery can be dramatically reduced [7-9].

Because the SOC cannot be directly measured, it is imperative to use an algorithm that can accurately estimate it, based on certain battery physical quantities (e.g., battery voltage and current). The Coulomb counting method $[7,10]$ and the open circuit voltage method $[7,11,12]$ are the two most used methods for SOC estimation. Coulomb counting method makes full use of the current measurement since the SOC is defined as the integration of current over the time, divided by the battery capacity. The accuracy of this method is related to the current measurement error, and to 
the battery capacity and the Coulombic efficiency. Moreover, the initial SOC should be known in order to estimate the actual SOC of the battery. All these factors heavily affect the SOC estimation result in the Coulomb counting method and are hard to be ignored. Since the open circuit voltage $(\mathrm{OCV})$ is monotonically decreasing while the battery is discharging, an OCV-SOC lookup table is able to predict the battery SOC. Nevertheless, for an accurate OCV measurement, the battery has to be rested for hours in order to reach its electrochemical equilibrium. Consequently, the applicability of this method for SOC estimation in real-life applications is questionable. Wei et al. [13] estimate SOC online by identifying the OCV through a multi-timescale estimator, which is efficient in the calculation. The estimated SOC relies heavily on the look-up table, but the OCV-SOC relationship is dependent on the temperature and changes while the battery is aging. Data-driven methods based on neural networks and regression models are also applied to estimate the SOC [14,15]. The accuracy of data-driven methods relies on the features of the training samples. It means that accurate SOC estimation is guaranteed only if the test data are similar to the training samples. In order to meet the requirement of various applications, SOC estimation methods must be both accurate and robust. Therefore, model-based methods are proposed for SOC estimation. For these methods, the difference between the measured battery terminal voltage and the model estimated voltage is utilized to correct the SOC. Furthermore, model-based methods are insensitive to the initial SOC and measurement noise. Kalman filter [16-18], H infinity filter [19,20], PI-observer [21], Particle filter [22], RTLS-based observer [23], FBCRLS-based observer [24] etc. are applied to calculate the correcting gain in the SOC estimation structure. Among the aforementioned approaches, Extended Kalman filters (EKF) offer a good tradeoff between estimation accuracy and computing burden for real applications.

According to the accuracy and suitability for different applications, different types of battery performance models have been developed, such as electrochemical models, statistically-based models, and electrical models. Electrochemical models are conventional models that use the equations governing the electrochemical phenomena (chemical reactions) that occur in a battery cell $[25,26]$. The implementation of these models requires extended knowledge about the battery chemical, mechanical and electrical properties and thus they are more appropriate for battery design optimization process than for battery SOC estimation. Recently, there have also been some efforts on using reduced order electrochemical for SOC estimation [27].

Statistically-based models rely on machine learning methods, such as, neural network, support vector machines; however, large numbers of training samples are needed for guaranteeing its accuracy and robustness, which limits its usage in real applications. Electrical models have a simple and concise structure, using simple circuit components (e.g., resistors, capacitors etc.) for estimating the battery voltage [28-30]. Furthermore, it is more effective for implementing the battery characteristics to a BMS by electrical model. The parameters of the electrical model are changing under different conditions of SOC, C-rate, temperature, as presented in [28]. Consequently, in order to parameterize a battery electrical model, which is able to accurately estimate the battery SOC and voltage for a wide range of operating conditions, the dependence of the battery parameters on the aforementioned states should be considered during the parametrization stage. Nevertheless, such an extended battery parameterization requires extensive laboratory tests, which are extremely time-consuming and cost-demanding and sometimes are not reflected in the model accuracy improvement. The sensitivity analysis of Li-ion battery model on battery parameters was studied in [31]; in this work, a simple Thévenin battery model was used and only the variation of the model's parameters with the SOC was considered. Similarly, in [32] the authors have evaluated the sensitivity of the estimated battery voltage to the changes with the SOC of the parameters' values of a second order RC-equivalent circuit. In none of the aforementioned papers, a thorough investigation on the influence of the Li-ion battery parameters' variation (with SOC and temperature) on the accuracy of the estimated battery SOC and voltage estimation was carried out. Therefore, in this paper a sensitivity analysis was performed, in order to observe the influence of the battery model parameters variation with SOC and temperature, on the 
accuracy of the proposed equivalent electrical circuit model and subsequently on the accuracy of the SOC estimation. The aging dependency is not considered in this work.

The remainder of this paper is organized as follows: the battery model is introduced in Section 2. The identification of the parameters of the battery equivalent electrical circuit (EEC), which was carried out based on laboratory measurements is described in Section 3. The following section presents the EKF methodology, which was used for estimating the battery SOC. The SOC and voltage estimation accuracy of the EKF method is evaluated in Section 5. The last section evaluates the sensitivity of the battery SOC and voltage estimation on the changes of EEC parameters.

\section{Battery Model Based on EEC Parameterization}

The equivalent electric circuit (EEC) models are an effective approach to represent the dynamic behavior of Li-ion batteries. Depending on the application and the required accuracy, different types of battery EEC models have been developed. The Rint model, the first order RC-model, and the second order RC-model, as well as the model based on impedance spectroscopy, have been proposed for predicting the battery voltage [28,33]. In this work, the dynamic behavior of the LTO-based battery was modeled using the second-order RC-equivalent circuit that is presented in Figure 1.

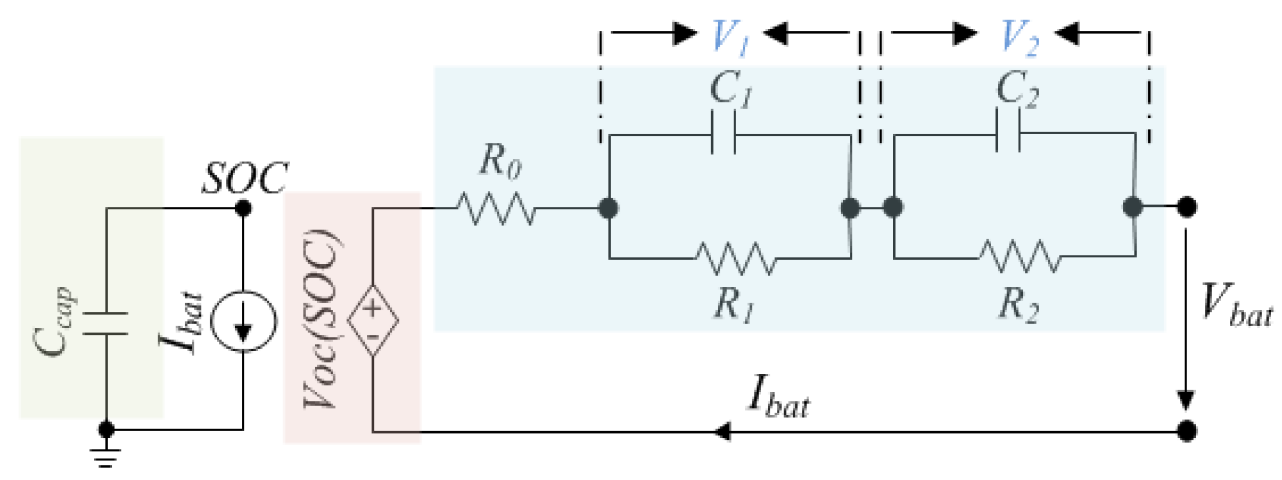

Figure 1. Proposed equivalent electrical model.

On the left-hand side, the capacitor $\mathrm{C}_{c a p}$ and the current-controlled source are used to model the capacity and the SOC of the battery cell. On the right-hand side, the electrical circuit representation consists of a controlled voltage source, a series resistor, and two RC networks. The resistor, $R_{0}$ represents the battery ohmic resistance, and it is responsible for the instantaneous voltage drop during charging/discharging [34]. The parameters, $R_{1}, R_{2}, C_{1}, C_{2}$, are used to describe the transient behavior of the battery cell. The $R_{1}$ and $C_{1}$ are responsible for the fast voltage response and represents the charge transfer resistance and electrochemical double layer capacitance, respectively, while $R_{2}$ and $C_{2}$ are responsible for the slow voltage response and are used to the model for the diffusion process. All the EEC parameters are dependent on SOC, temperature and current. The two parts are connected by the voltage source $V_{O C}$ (SOC), which is used to model the OCV of the battery that is dependent on SOC.

In this proposed dynamic model of the LTO-based battery cell, the self-discharge was not considered, mainly because it does not affect the dynamic response of Li-ion batteries. Meanwhile, the terminal voltage of the proposed model, $V_{b a t}$, was calculated for discharging conditions as follows:

$$
V_{b a t}=V_{O C}-V_{1}-V_{2}-R_{0} I_{b a t}
$$

where $V_{O C}$ represents the open circuit voltage, $V_{1}$ and $V_{2}$ is the voltage across the $R_{1} C_{1}$ network, $R_{2} C_{2}$ network, respectively, $I_{b a t}$ is the instantaneous battery current, whose sign is taken to be positive when the battery is charging and negative during discharging. 
The battery SOC was defined according to the following mathematical relationship:

$$
\mathrm{SOC}=\mathrm{SOC}_{i}+\frac{1}{\mathrm{C}_{\text {cap }}} \int_{0}^{t} I_{b a t} d t
$$

where $\mathrm{SOC}_{i}$ represents the initial $\mathrm{SOC}, C_{c a p}$ is the is the nominal battery capacity.

From Equation (2), it is noted that SOC calculation is based on the integration of current. The obtained SOC is used further as the reference SOC during the EKF estimation method.

\subsection{Experimental Set-Up}

This research work was carried out on a commercially available 13 Ah high-power LTO $\left(\mathrm{Li}_{4} \mathrm{Ti}_{5} \mathrm{O}_{12}\right)$-based Li-ion battery cell. The electrical and thermal parameters of this LTO-based battery cell are summarized in Table 1.

During the experiments, the LTO-based Li-ion battery cell was placed in a temperature chamber, as illustrated in Figure 2. The temperature of the battery cell was monitored using a type-K thermocouple; furthermore, the temperature values referred in this analysis are the ones measured on the surface of the LTO-based Li-ion battery cell.

Table 1. Specification of the Li-ion battery cell used in this study.

\begin{tabular}{cc}
\hline Property & Title 2 \\
\hline Nominal capacity & $13 \mathrm{Ah}$ \\
Nominal voltage & $2.26 \mathrm{~V}$ \\
Voltage range & $1.5-2.9 \mathrm{~V}$ \\
Current range & $\pm 130 \mathrm{~A}$ \\
Operating temperature range & $-40{ }^{\circ} \mathrm{C}$ to $55^{\circ} \mathrm{C}$ \\
\hline
\end{tabular}

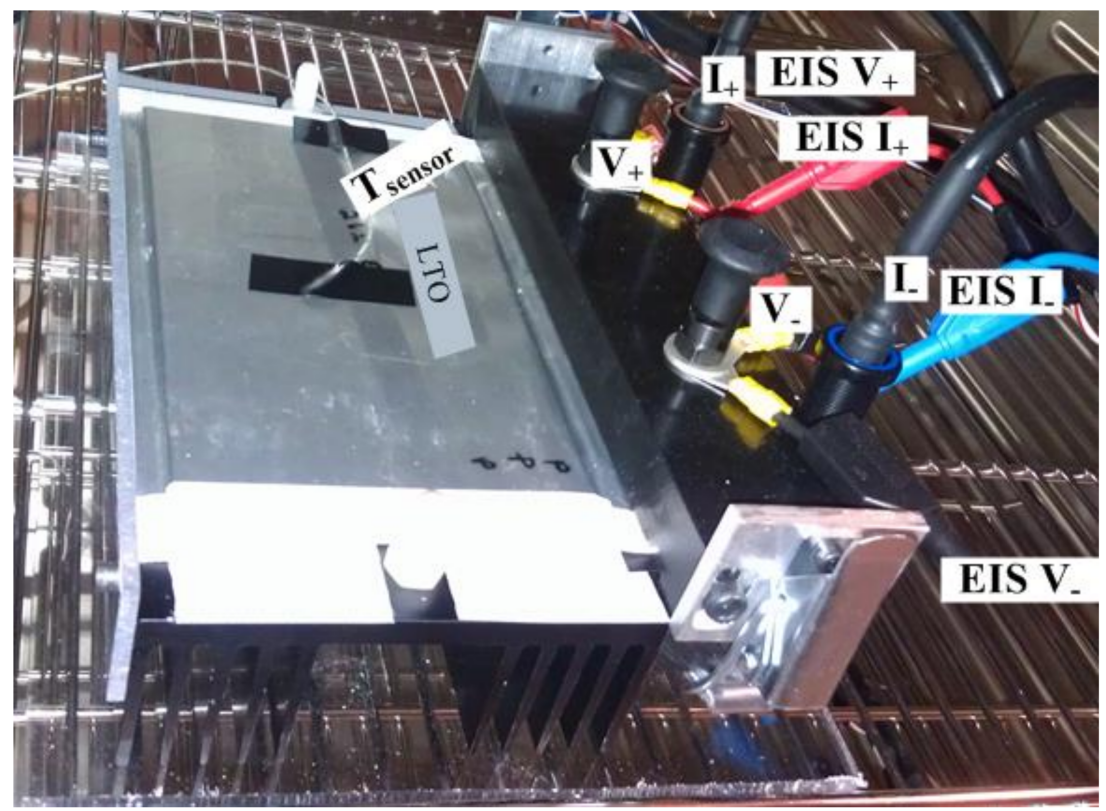

Figure 2. LTO-based Li-ion battery cell placed in a temperature chamber.

\subsection{Battery Capacity}

The capacity of the battery is influenced by the C-rate and temperatures. Thus, the capacity of the studied LTO-based battery cell was measured for different temperatures (i.e., $5-45^{\circ} \mathrm{C}$ in steps of $10^{\circ} \mathrm{C}$ ) and 8 different $\mathrm{C}$-rates (i.e., from $\mathrm{C} / 4$ to $9 \mathrm{C}$ ). During charging, the capacity was measured 
considering a constant current-constant voltage procedure, while during discharging a constant current procedure was applied. Figure 3 illustrates the impact of the $\mathrm{C}$-rate on the voltage during the capacity measurements at $25^{\circ} \mathrm{C}$ for different C-rates.

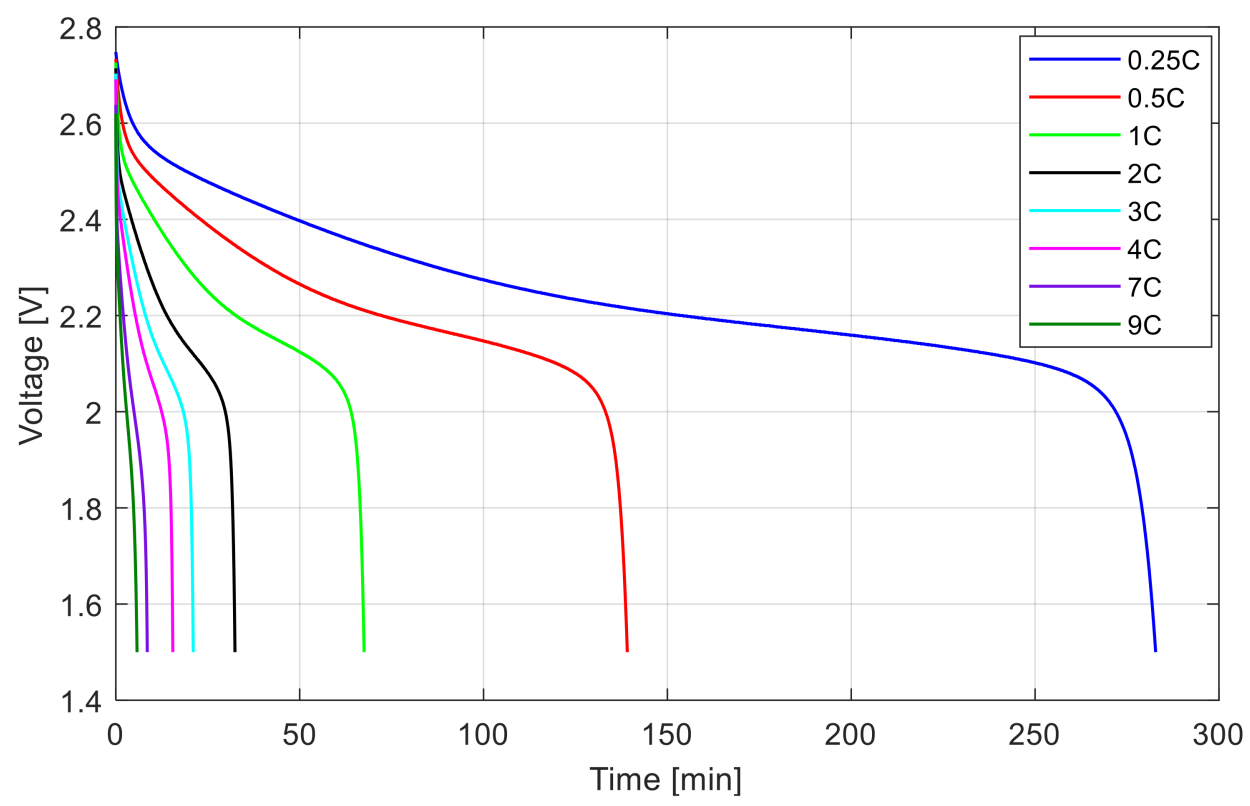

Figure 3. Voltage changes with discharging rates.

\subsection{Battery $O C V$}

Despite the linear model of the LTO battery, the static relationship between VOC and SOC is intrinsically nonlinear [35]. SOC represents the amount of charge remained in the battery compared with the full capacity, and the relationship between OCV and SOC is a static characteristic of the battery, which is not changing with the load profile, but changes with temperature and age.

The nonlinearity of the model increases the complexity of the performance analysis of the estimators [35]. To deal with this problem, a high order polynomial function is introduced. The quadratic optimization is applied to guarantee the diminishing of OCV with the decrease of SOC [36].

The relationship between the SOC and OCV was determined by charging and discharging with 0.5C (i.e., $6.5 \mathrm{~A}$ ) the LTO-based battery cell at different temperatures $\left(5,15,25,35,45^{\circ} \mathrm{C}\right.$ ). Based on the OCV-SOC curves obtained experimentally for the LTO-based battery (see Figure 4), the average between the charge and discharge curves is taken as the relationship between OCV and SOC. The average between charge and discharge of the OCV-SOC characteristic at different temperatures is presented in Figure 5. Further on, the average of OCV-SOC curves was approximated by a polynomial function, as shown in Equation (3), where the coefficients are given in Table 2 for all considered temperatures. The mean absolute error considering the experimental results at $25^{\circ} \mathrm{C}$ is $0.0073 \mathrm{~V}$, which proves the accuracy of the curve fitting method:

$$
V_{o c}=f(\mathrm{SOC})=\sum_{i=0}^{8} p_{i} \mathrm{SOC}^{i},
$$


Table 2. Polynomial approximation of the OCV-SOC characteristic.

\begin{tabular}{cccccc}
\hline \multirow{2}{*}{ Coefficient } & \multicolumn{5}{c}{ Title $\mathbf{3}$} \\
\cline { 2 - 6 } & $\mathbf{5}{ }^{\circ} \mathbf{C}$ & $\mathbf{1 5}{ }^{\circ} \mathbf{C}$ & $\mathbf{2 5}{ }^{\circ} \mathbf{C}$ & $\mathbf{3 5}{ }^{\circ} \mathbf{C}$ & $\mathbf{4 5}{ }^{\circ} \mathbf{C}$ \\
\hline $\mathrm{p}_{0}$ & 2.1243 & 2.0301 & 1.8160 & 1.8778 & 1.860 \\
$\mathrm{p}_{1}$ & 0.1511 & 2.1737 & 7.9113 & 6.1879 & 6.667 \\
$\mathrm{p}_{2}$ & 7.3333 & $-1.365 \times 10^{1}$ & $-7.341 \times 10^{1}$ & $-5.680 \times 10^{1}$ & $-6.177 \times 10^{1}$ \\
$\mathrm{p}_{3}$ & $-8.047 \times 10^{1}$ & $3.177 \times 10^{1}$ & $3.455 \times 10^{2}$ & $2.689 \times 10^{2}$ & $2.947 \times 10^{2}$ \\
$\mathrm{p}_{4}$ & $3.784 \times 10^{2}$ & $3.906 \times 10^{1}$ & $-8.888 \times 10^{2}$ & $-7.004 \times 10^{2}$ & $-7.767 \times 10^{2}$ \\
$\mathrm{p}_{5}$ & $-9.307 \times 10^{3}$ & $-3.292 \times 10^{2}$ & $1.283 \times 10^{3}$ & $1.033 \times 10^{3}$ & $1.166 \times 10^{3}$ \\
$\mathrm{p}_{6}$ & $1.251 \times 10^{3}$ & $6.321 \times 10^{2}$ & $-1.0004 \times 10^{3}$ & $-8.355 \times 10^{2}$ & $-9.722 \times 10^{2}$ \\
$\mathrm{p}_{7}$ & $-8.693 \times 10^{2}$ & $-5.262 \times 10^{2}$ & $3.643 \times 10^{2}$ & $3.283 \times 10^{2}$ & $4.0437 \times 10^{2}$ \\
$\mathrm{p}_{8}$ & $2.439 \times 10$ & $1.648 \times 102$ & $-3.739 \times 10^{1}$ & $-4.279 \times 10^{1}$ & $-6.055 \times 10^{1}$ \\
\hline
\end{tabular}

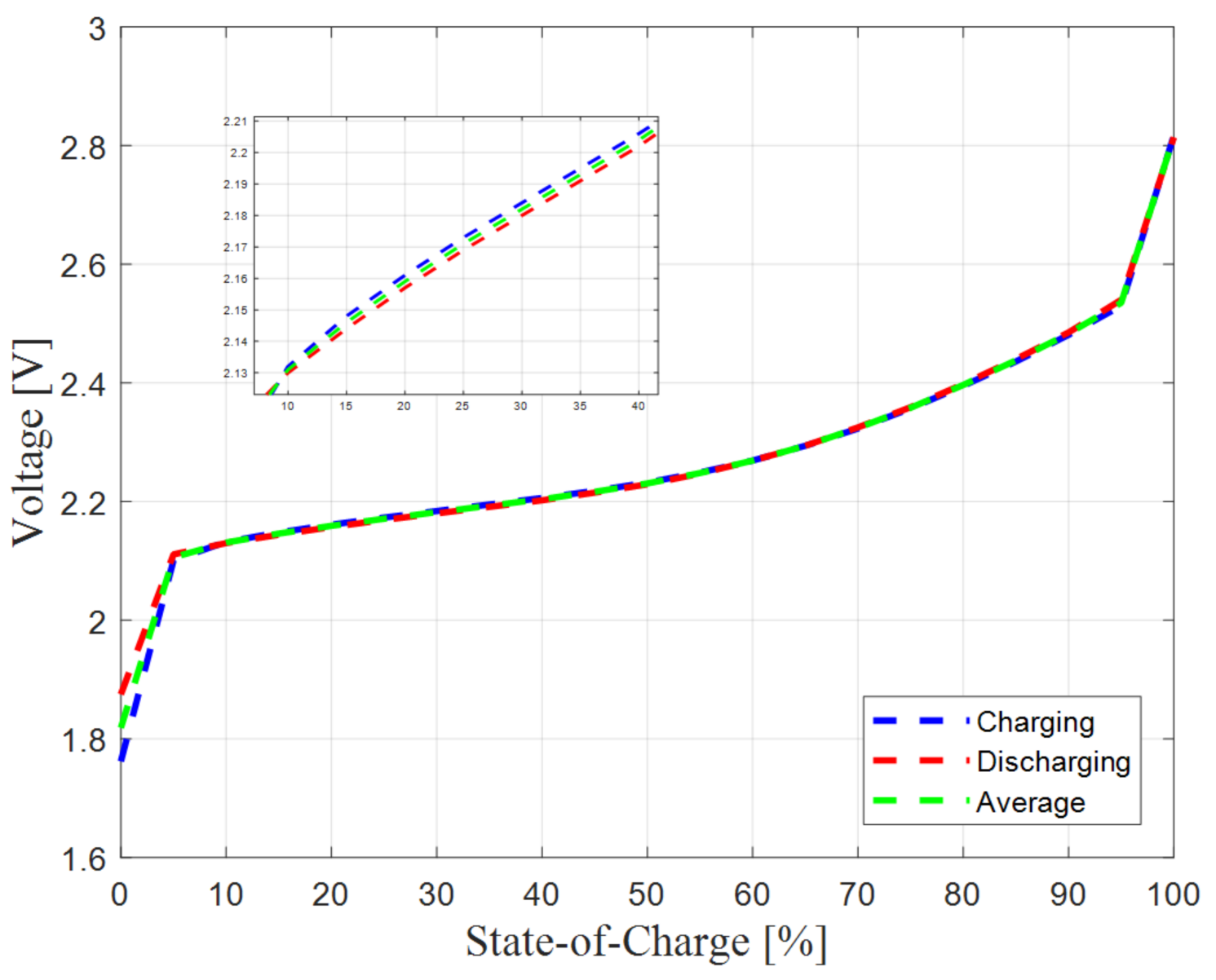

Figure 4. The OCV-SOC characteristic of the LTO-based battery measured at $\mathrm{T}=25^{\circ} \mathrm{C}$. 


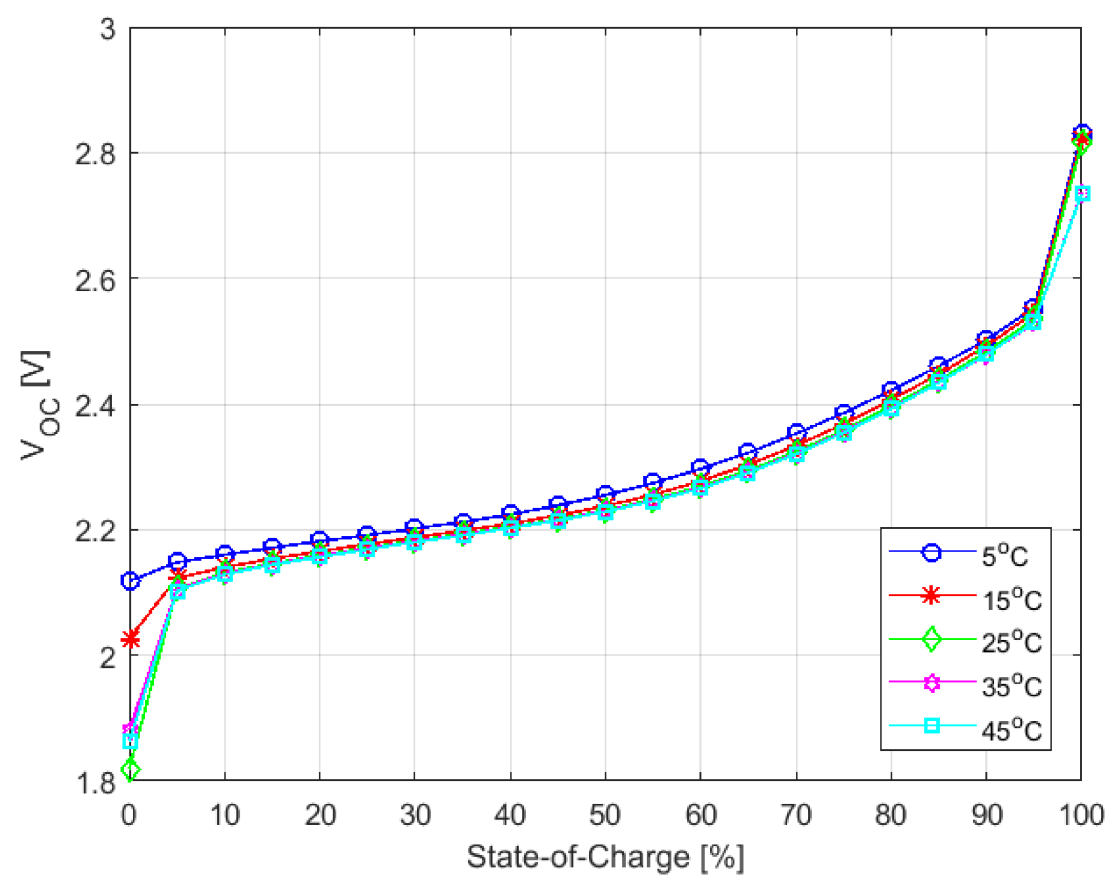

Figure 5. The OCV-SOC characteristic of the LTO-based battery measured at different temperatures.

Considering the equivalent circuit model for the LTO battery, presented in Figure 1, the state-space equation can be written as given in Equation (4):

$$
\left[\begin{array}{c}
\dot{V}_{1} \\
\dot{V}_{2} \\
\mathrm{SOOC}
\end{array}\right]=\left[\begin{array}{ccc}
-\frac{1}{R_{1} C_{1}} & 0 & 0 \\
0 & -\frac{1}{R_{2} C_{2}} & 0 \\
0 & 0 & 0
\end{array}\right] \cdot\left[\begin{array}{c}
V_{1} \\
V_{2} \\
\mathrm{SOC}
\end{array}\right]+\left[\begin{array}{c}
\frac{1}{C_{1}} \\
\frac{1}{C_{2}} \\
\frac{1}{C_{\text {cap }}}
\end{array}\right] \cdot I_{\text {bat }},
$$

In this equation, the SOC of the battery and the voltages across the two RC networks are selected to be system state variable. The battery parameters which need to be estimated are $R_{0}, R_{1}, C_{1}, R_{2}$, and $C_{2}$.

\section{Parameter Identification}

Apart from the OCV, the other parameters of the EEC $\left(R_{0}, R_{1}, R_{2}, C_{1}, C_{2}\right)$ have been estimated using the hybrid pulse power characterization (HPPC) method. The HPPC profile, which was applied to the LTO-based battery cell, is shown in Figure 6. The current pulse characterization method consists in applying a constant current pulse of a certain amplitude, $\Delta I$ to the battery and measuring the resulting change in the battery voltage, $\Delta V$, either during and after the pulse.

The parameters of the EEC have been identified for SOCs between $5 \%$ and $95 \%$ with a $5 \%$ SOC resolution. At each SOC, both charging and discharging current pulses of various amplitudes were applied. Based on the voltage response to a current pulse (see Figure 7), the parameters $R_{0}, R_{1}, R_{2}, C_{1}$, and $C_{2}$ have been identified.

When there is a sudden change in the current, a voltage drop, $\left(\Delta V_{0}\right)$ caused by the ohmic polarization appears instantaneously; then the voltage drop completes the transient process with an exponential approximation until the voltage will return to a steady state value. Therefore, the ohmic resistance, $R_{0}$, was determined according to Equation (5), considering that the voltage before the current pulse changes is $V_{0}$, the voltage at the end of the instantaneous voltage drop (i.e., after $0.1 \mathrm{~s}$ ) is $V_{1}$. 

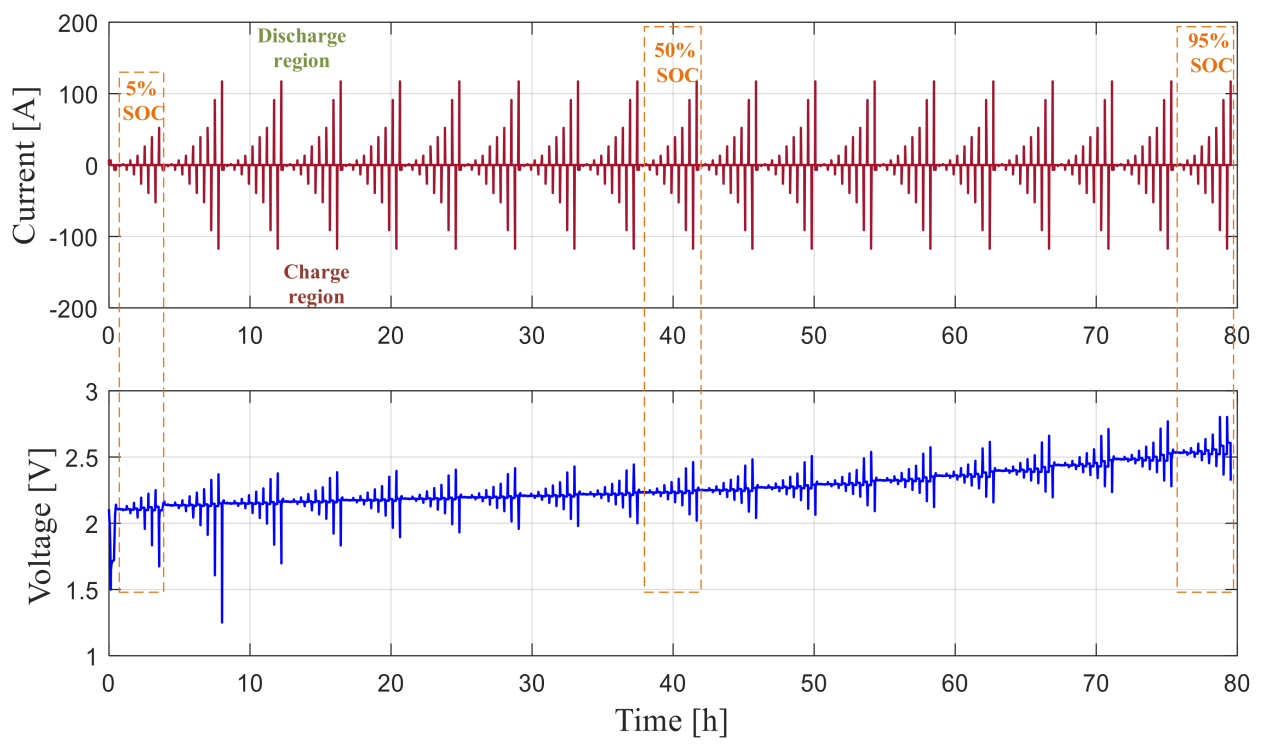

Figure 6. Current pulse and voltage profiles.

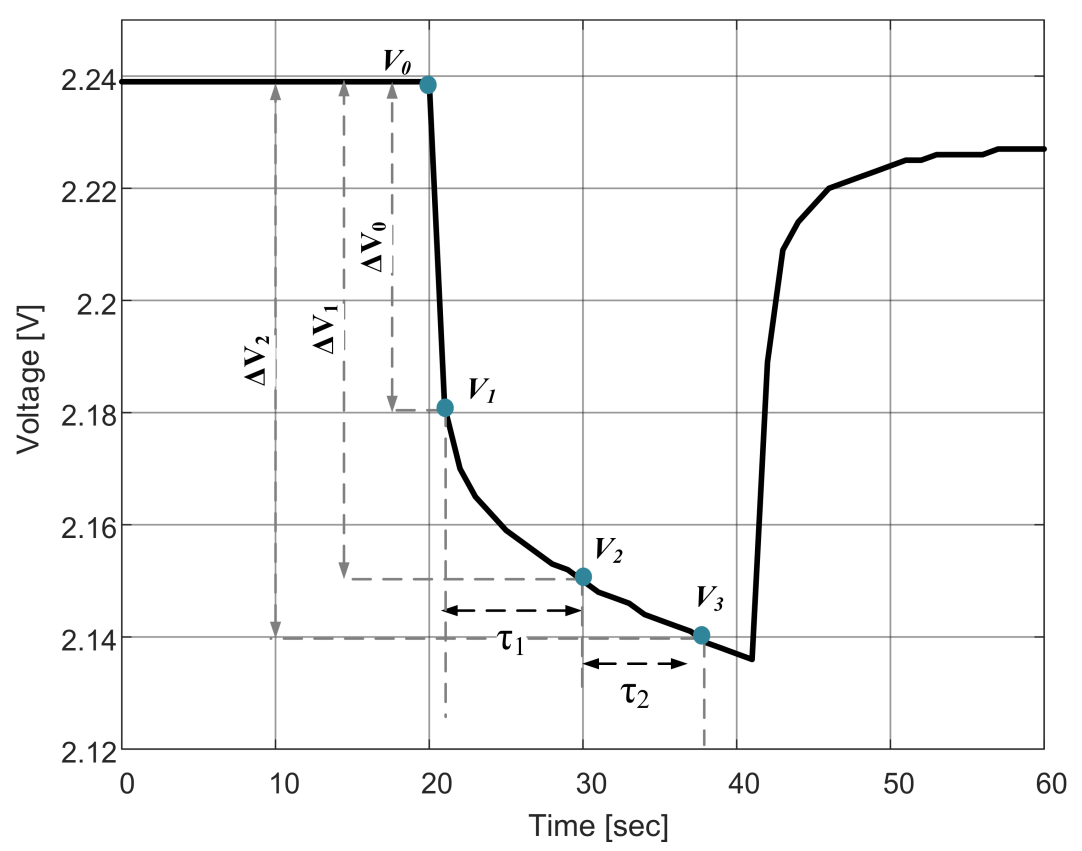

Figure 7. Voltage response of LTO-based Li-ion battery cell for a $1 \mathrm{C}$-rate current pulse at $25^{\circ} \mathrm{C}$.

$$
R_{0}=\frac{\Delta V_{0}}{\Delta I}=\frac{\left|V_{0}-V_{1}\right|}{I},
$$

In order to extract the parameters of the EEC, related to the battery transient response, $R_{i}$ and $C_{i}$, which are responsible for the fast voltage response (first $R C$ network) and for the slow voltage response (second RC network), the following approach was followed. Resistances $R_{1}$ and $R_{2}$ were determined according to Ohm's Law, as given in Equations (6) and (7), where $V_{2}$ and $V_{3}$ are measured during the current pulse after 10 and $18 \mathrm{~s}$, respectively. The capacitances $C_{1}$ and $C_{2}$ were calculated based on the 
time constant of RC parallel networks, which is given in Equation (8). Furthermore, the time constant of the two RC parallel networks was determined according to the methodology presented in [37]:

$$
\begin{gathered}
R_{1}=\frac{\Delta V_{1}}{\Delta I}=\frac{\left|V_{1}-V_{2}\right|}{I}, \\
R_{2}=\frac{\Delta V_{2}}{\Delta I}=\frac{\left|V_{2}-V_{3}\right|}{I} \\
\tau_{i}=R_{i} \cdot C_{i},
\end{gathered}
$$

where $\tau_{i}$ represents the time constant of the first and second RC network, $R_{i}$ and $C_{i}$ represent the resistance and the capacitance of the RC networks, $i$ is 1 or 2 and corresponds to the first and second RC networks.

Figure 8 shows the results of the EEC parameters' identification process (based on Equations (5)-(8)) that were obtained for different temperatures and various SOCs, when the discharging pulse case was considered. Similar results were obtained for the charging pulse case.

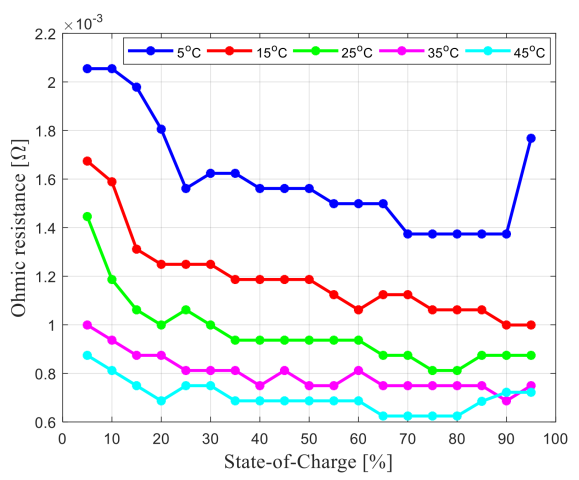

(a)

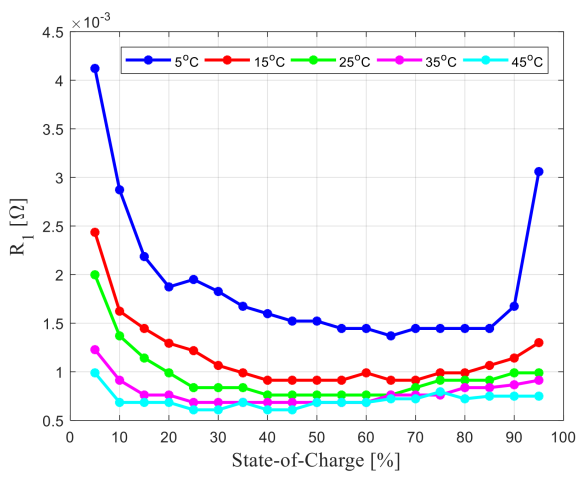

(b)

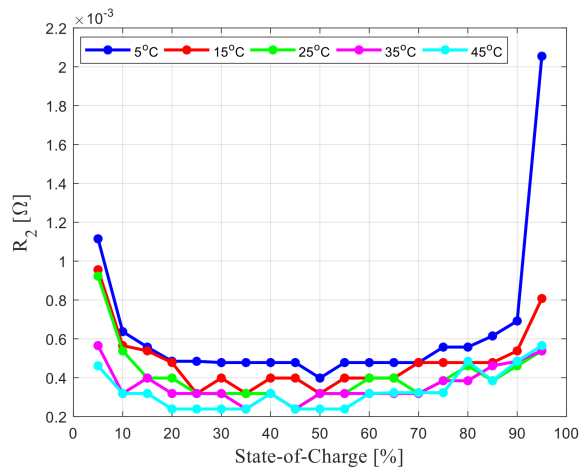

(d)

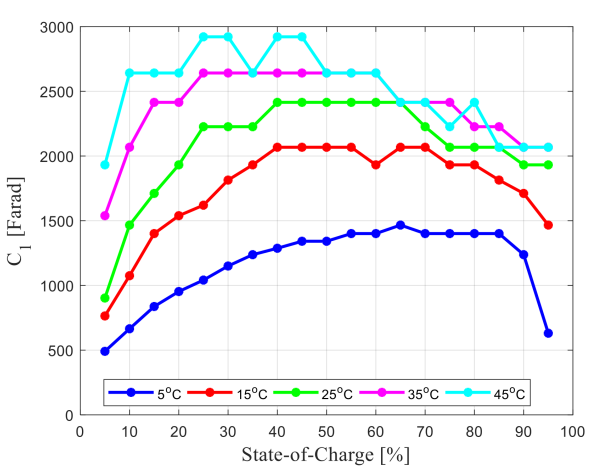

(c)

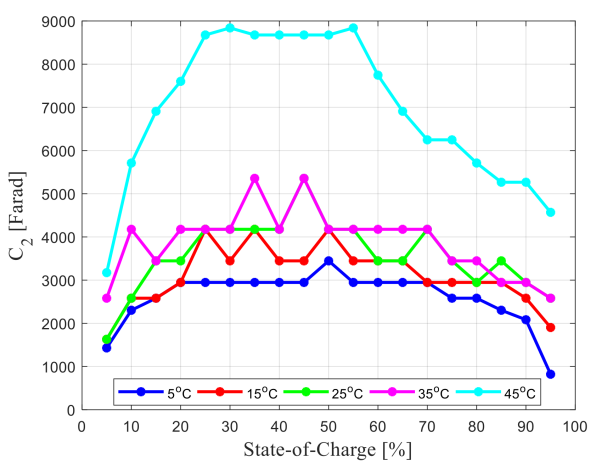

(e)

Figure 8. Variation of EEC parameters $(\mathbf{a}) R_{0} ;(\mathbf{b}) R_{1} ;(\mathbf{c}) C_{1} ;(\mathbf{d}) R_{2} ;(\mathbf{e}) C_{2}$ with SOC and temperature. 
As it can be observed in Figure 8, the ohmic resistance, $R_{0}$, as well as resistances $R_{1}$ and $R_{2}$ significantly decrease with the increase in temperature. Meanwhile, the capacitances, $C_{1}$ and $C_{2}$, are increasing with the increase in temperatures. Furthermore, all five parameters are changing with SOC. These experimental results show dependence between battery parameters and the operating conditions and justify the need to analyze the sensitivity of the battery model to the changes in the parameters.

\section{State-of-Charge Estimation Based on Extended Kalman Filter Method}

Kalman filters were firstly used in the area of aerospace. They are able to estimate the optimal state of a system on the basis of a series of data observed from the state space equation in the linear space. For the purpose of achieving the states also in a nonlinear system, EKF is proposed. The EKF dynamically linearizes the nonlinear model at the working point by a Taylor Series expansion.

The battery state space function is also a nonlinear system, especially in the lower and higher SOC ranges.

Considering the EEC presented in Figure 1, the battery model is expressed as follows:

$$
\left\{\begin{array}{c}
V_{b a t}=V_{O C}-V_{1}-V_{2}-I \cdot R_{0} \\
I=\frac{V_{1}}{R_{1}}+C_{1} \cdot \frac{d V_{1}}{d t}=\frac{V_{2}}{R_{2}}+C_{2} \cdot \frac{d V_{2}}{d t}
\end{array},\right.
$$

First equation presented in the Equation (9), represents the battery voltage, $V_{b a t}$. From Equation (9), we can obtain the state space function of the two RC model as follows:

$$
\left\{\begin{array}{l}
X_{k+1}=A \cdot X_{k}+B \cdot I_{k} \\
Y_{k+1}=C \cdot X_{k}+D \cdot I_{k}
\end{array}\right.
$$

where:

$$
\begin{gathered}
X_{k}=\left[\begin{array}{c}
V_{1} \\
V_{2} \\
\mathrm{SOC}
\end{array}\right]_{k}, A=\left[\begin{array}{ccc}
-\frac{T}{R_{1} \cdot C_{1}}+1 & 0 & 0 \\
0 & -\frac{T 1}{R_{2} \cdot C_{2}}+1 & 0 \\
0 & 0 & 1
\end{array}\right], B=\left[\begin{array}{l}
\frac{T}{C_{1}} \\
\frac{T}{C_{2}} \\
-\frac{T}{C_{c a p}}
\end{array}\right], \\
C=\left[-1-1 \frac{\partial f(\mathrm{OCV})}{\partial \mathrm{SOC}}\right], D=R_{0}, Y_{k}=U_{t, k} .
\end{gathered}
$$

where $T$ is the step time response. In this equation, the SOC of the battery and the voltages across the two RC circuit are selected to be system state variable. The EKF computes the Jacobian matrix from (9), then the matrix $C$ is obtained. In Equation (10), the approximation $e^{A \cdot T} \approx I+A \cdot T$ is using to discrete the battery state space equation [5].

After establishing the state space equation, the steps for SOC estimation by EKF are listed in Table 3.

Table 3. The process of EKF for SOC estimation.

\begin{tabular}{cc}
\hline \multicolumn{2}{c}{ Prediction } \\
\hline $\begin{array}{c}\text { State Prediction } \\
\text { Covariance Prediction }\end{array}$ & $\begin{array}{c}X_{k+1 \mid k}=A \cdot X_{k}+B \cdot I_{k} \\
P_{k+1 \mid k}=A \cdot X_{k} \cdot A^{T}+Q_{k}\end{array}$ \\
\hline Kalman Gain Matrix & Update \\
State Estimation & $K_{k}=P_{k+1 \mid k} \cdot C^{T} \cdot\left(C \cdot P_{k+1 \mid k} \cdot A^{T}+W_{k}\right)^{-1}$ \\
Covariance Estimation & $X_{k+1}^{*}=X_{k+1 \mid k}+K_{k} \cdot\left(y_{k}-C \cdot X_{k}-D \cdot I_{k}\right)$ \\
$P_{k+1}=\left(I-K_{k} \cdot C\right) \cdot P_{k+1 \mid k}$
\end{tabular}

In Table $3, Q$ is the covariance of the process noise, $W$ is the covariance of observation noise, and $P$ is the error covariance. The initial values of the three covariance matrices should be set before the EKF 
estimation. After giving initial values, the EKF is capable of converging to the optimal SOC through the iterative process summarized in Table $3 . X_{k+1 \mid k}$ and $P_{k+1 \mid k}$ are the estimated state and covariance matrix, respectively. Afterward, the Kalman filter gain and the covariance matrix are updated, and the estimated state is corrected by the updated gain. The update step utilizes the information from the new measurement for improving the a posteriori state estimation. In this way, the EKF can achieve the best tradeoff between sensor measurement and model output for an accurate state estimation. The parameter $X_{k+1}^{*}$ from Table 3, is the final state estimation of the EKF. The structure of the EKF calculating steps is presented in Figure 9a. The EKF is able to estimate the battery's SOC on the basis of only the former state and the current measurement. Thus, it does not rely on the battery historical data and has a much higher computation efficiency. Moreover, according to the closed structure of the EKF, the algorithm is insensitive to the initial SOC value. The flowchart of the EKF-based SOC estimation is shown in Figure 9b.

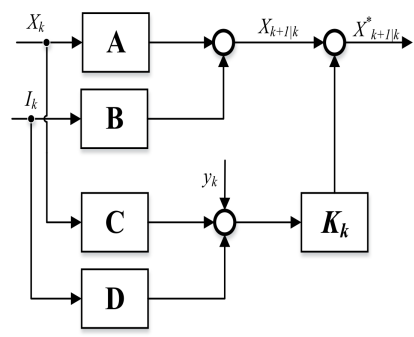

(a)

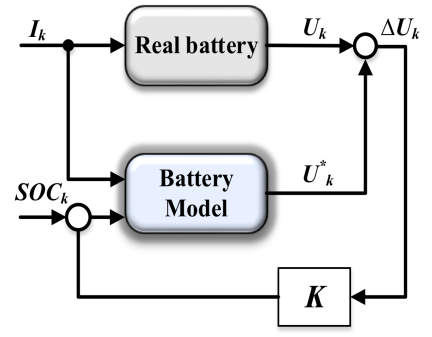

(b)

Figure 9. (a) The structure for EKF calculation; (b) The schematic diagram of EKF on SOC estimation.

\section{State-of-Charge Estimation Results}

The SOC of the LTO-based Li-ion battery is estimated using the EKF method, which is presented in Figure 9b. The structure of the SOC estimation method is illustrated in Figure 10. The EKF utilizes the voltage measurement from the battery and the load current profile applied to the battery, in order to estimate the SOC. Then, in order to improve the accuracy of the battery model, the estimated SOC and the battery current are substituted into the established battery model for updating parameter. In order to test the proposed SOC estimation method for the LTO-based battery, a step discharge profile was used. The considered battery cell was discharged, from a totally charged state, with $6.5 \mathrm{~A}$ (0.5C-rate) in steps of $5 \% \triangle \mathrm{SOC}$. During the experiment, the data (i.e., current and voltage) were recorded with a sampling time of five seconds.

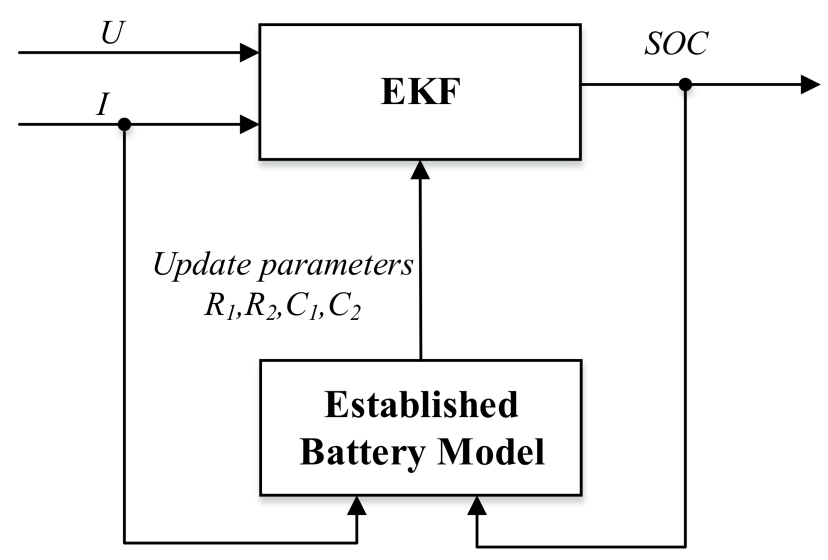

Figure 10. The structure of the SOC estimation method. 
The result of the EKF based SOC estimation, for a temperature of $25^{\circ} \mathrm{C}$ is shown in Figure 11a. Furthermore, a comparison between the laboratory measured battery voltage and the estimated battery voltage by the model is presented in Figure 11b. In order to test the SOC estimation, the initial SOC of the EKF method was arbitrarily set to $0.7(70 \%)$ for further analysis in this paper.

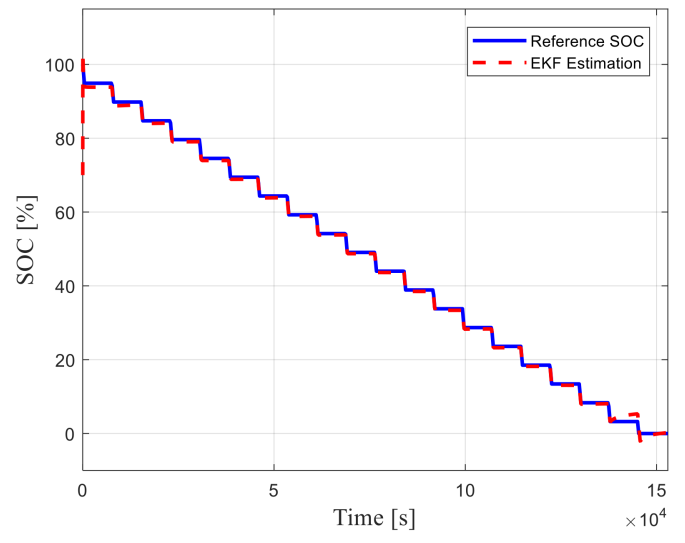

(a)

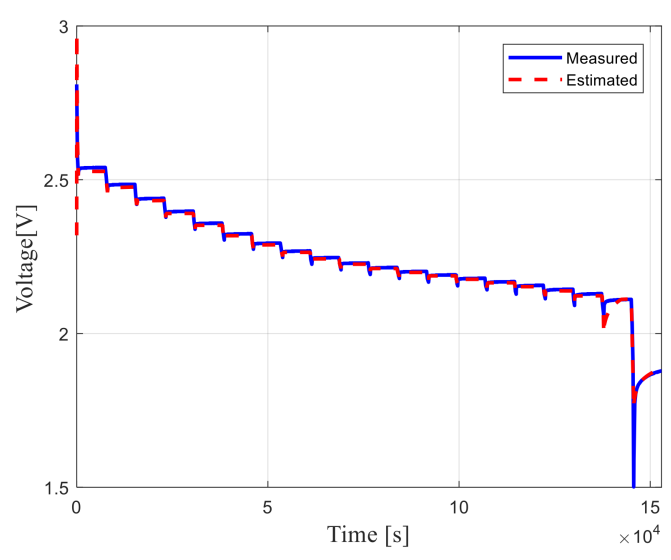

(b)

Figure 11. (a) SOC estimation results at $25^{\circ} \mathrm{C}$ when the initial SOC is set to $70 \%$; (b) Comparison between measured and estimated voltage $25^{\circ} \mathrm{C}$.

Moreover, Figure 12a shows a discharged pulse, where random SOC values have been assigned to initialized the EKF estimation method. The initial SOC used in EKF method has been $50 \%, 70 \%$, and $100 \%$, while the SOC reference is actually $100 \%$. The results of these experiments show that in the beginning there is a high error in the SOC estimation (50\%,30\%), then the estimated SOC converge to the reference (steady-state value) after an acceptable settling time (up to $100 \mathrm{~s}$ ). Then the SOC stays with the reference, overlapping with very small errors. The error band of the SOC estimation method has to be between the $\pm 2 \%$ [21,38]. The obtained SOC estimation error, when the initial SOC for the EKF has been set $50 \%, 70 \%$ and $100 \%$ are showed in Figure 12b.

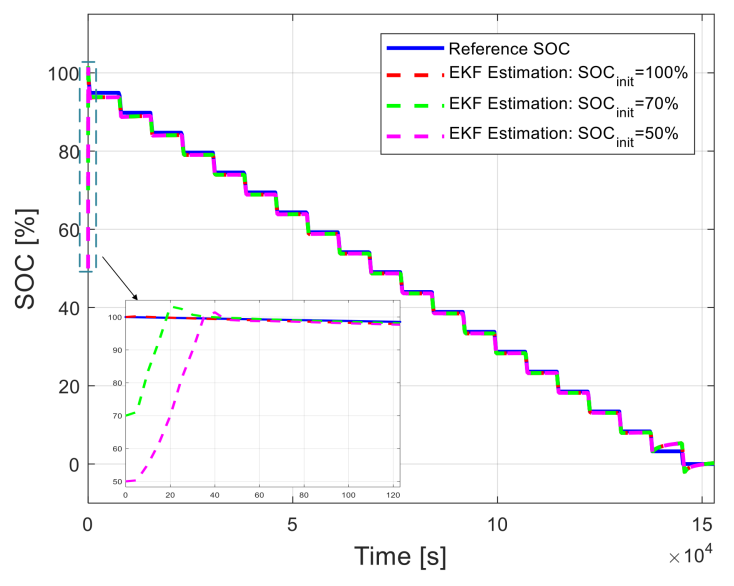

(a)

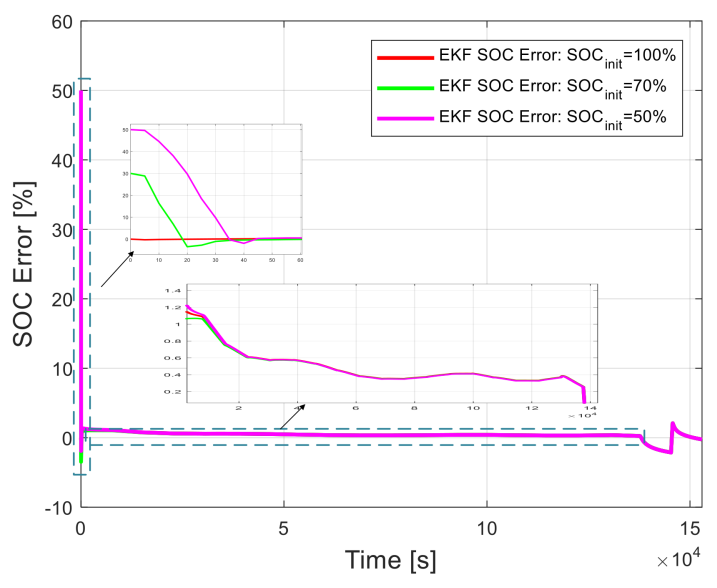

(b)

Figure 12. (a) Experimental results of EKF method at $25{ }^{\circ} \mathrm{C}$ considering different initial SOC assignments $(50 \%, 70 \%, 100 \%)$; (b) SOC estimation error curves at $25^{\circ} \mathrm{C}$. 
Furthermore, the mean absolute error between the measured and estimated SOC and voltage profiles were computed according to Equation (10):

$$
|\bar{\varepsilon}|=\left|\overline{x_{r e f}(i)-x_{e s t}(i)}\right|,
$$

where $x_{\text {ref }}$ represents the voltage measured, and the reference SOC, respectively and $x_{\text {est }}$ represents the modeled voltage, and the SOC estimated, respectively. The SOC and voltage estimation mean errors are summarized in Table 4, while the maximum SOC and voltage estimation errors are summarized in Table 5.

Using the proposed model based on the EKF, the SOC and voltage of the battery were estimated also for a similar discharge profile at four other temperatures, i.e., $5^{\circ} \mathrm{C}, 15^{\circ} \mathrm{C}, 35^{\circ} \mathrm{C}, 45^{\circ} \mathrm{C}$. The obtained SOC and voltage mean estimation errors are also summarized in Table 4 . As it can be observed the proposed model estimates with very good accuracy both the SOC and voltage of the LTO-based battery; the highest mean estimation error was $0.0144 \mathrm{~V}$ (at $\mathrm{T}=45^{\circ} \mathrm{C}$ ) for voltage and $1.16 \%$ (at $35^{\circ} \mathrm{C}$ ) for SOC. The maximum SOC and voltage estimations errors (i.e., $5.57 \%$ and $0.55 \mathrm{~V}$, respectively) were obtained for a temperature of $5{ }^{\circ} \mathrm{C}$; nevertheless, for all the considered temperatures the maximum voltage and SOC estimation errors were obtained in the beginning of the simulations, when the SOC estimator was not able yet to capture the reference SOC.

Table 4. SOC and voltage mean estimnation errors.

\begin{tabular}{cccccc}
\hline \multirow{2}{*}{ Mean Error } & \multicolumn{5}{c}{ Temperature } \\
\cline { 2 - 6 } & $\mathbf{5}^{\circ} \mathbf{C}$ & $\mathbf{1 5}{ }^{\circ} \mathbf{C}$ & $\mathbf{2 5}{ }^{\circ} \mathbf{C}$ & $\mathbf{3 5}{ }^{\circ} \mathbf{C}$ & $\mathbf{4 5}{ }^{\circ} \mathbf{C}$ \\
\hline SOC $[\%]$ & 0.4440 & 0.8422 & 0.5437 & 1.1569 & 1.1422 \\
\hline Voltage $[\mathrm{V}]$ & 0.083 & 0.0087 & 0.0058 & 0.0172 & 0.0144 \\
\hline
\end{tabular}

Table 5. SOC and voltage maximum estimnation errors.

\begin{tabular}{cccccc}
\hline \multirow{2}{*}{ Max. Error } & \multicolumn{5}{c}{ Temperature } \\
\cline { 2 - 5 } & $\mathbf{5}^{\circ} \mathbf{C}$ & $\mathbf{1 5}{ }^{\circ} \mathbf{C}$ & $\mathbf{2 5}{ }^{\circ} \mathbf{C}$ & $\mathbf{3 5}{ }^{\circ} \mathbf{C}$ & $\mathbf{4 5}{ }^{\circ} \mathbf{C}$ \\
\hline SOC $[\%]$ & 5.5703 & 1.7172 & 2.1326 & 3.3254 & 2.2291 \\
\hline Voltage [V] & 0.5588 & 0.0570 & 0.272 & 0.1380 & 0.1242 \\
\hline
\end{tabular}

As one can observe in Figure 11, the proposed model is not able to estimate the voltage and the SOC of the studied LTO-based battery for SOCs close to $0 \%$. This lack of accuracy is caused by the fact that the model was parametrized considering a 5\% SOC resolution, as previously mentioned; however, for SOCs below $10 \%$, the voltage behavior of the battery changes steeply (i.e., decreases drastically), which suggests that for this interval, the battery model has to be parameterized considering a higher SOC resolution, e.g., $2 \%$ SOC steps instead of $5 \%$ SOC. 


\section{Sensitivity Analysis of Estimated SOC and Battery Voltage}

The sensitivity, of the proposed SOC estimation model, on the parameters of the battery model, was also analyzed. As previously mentioned, the parameters of the EEC were obtained for SOCs between $5 \%$ and $95 \%$ with $5 \%$ SOC resolution. In order to perform this sensitivity analysis, each parameter of the EEC was kept constant at a time (at the average value between the values obtained for each SOC at $0.5 \mathrm{C}$ ), while the other parameters were varying with the SOC. This analysis was repeated for all the considered five temperatures.

The obtained SOC and voltage estimation errors are summarized in Table 6. Furthermore, the measured and estimated voltage profiles, for the sensitivity analysis performed at $25^{\circ} \mathrm{C}$, are presented in Figure 13. In Table 6, the highlighted (grey shade) values represent the instances when the obtained errors for the case when the average for the parameter was used are higher than the errors for the case when the dependence on the SOC was considered. Moreover, Figure 14 shows the obtained errors in terms of SOC and voltage, respectively, when the initial SOC of the EKF method is set to be $70 \%$.

As one can observe, the SOC estimation is most sensitive with the changes in the values of the resistances and the capacitances of the RC-networks, while the battery voltage is most sensitive to the capacitance, $C_{1}$.

Table 6. Sensitivity analysis of the error of the SOC and battery voltage. Mean errors.

\begin{tabular}{ccccccc}
\hline \multirow{2}{*}{ Condition } & Mean Error & \multicolumn{5}{c}{ Temperature } \\
\cline { 3 - 7 } & & $\mathbf{5}{ }^{\circ} \mathbf{C}$ & $\mathbf{1 5}{ }^{\circ} \mathbf{C}$ & $\mathbf{2 5}{ }^{\circ} \mathbf{C}$ & $\mathbf{3 5}{ }^{\circ} \mathbf{C}$ & $\mathbf{4 5}{ }^{\circ} \mathbf{C}$ \\
\hline \multirow{2}{*}{$R_{0}$ constant } & SOC [\%] & 0.4463 & 0.8390 & 0.5420 & 1.543 & 1.1442 \\
& Voltage [V] & 0.0084 & 0.0088 & 0.0058 & 0.0172 & 0.0144 \\
\hline \multirow{2}{*}{$R_{1}$ constant } & SOC [\%] & 0.5166 & 0.8457 & 0.5221 & 1.1738 & 1.1235 \\
& Voltage [V] & 0.0083 & 0.0086 & 0.0056 & 0.0017 & 0.0136 \\
\hline \multirow{2}{*}{$C_{1}$ constant } & SOC [\%] & 0.8676 & 0.8675 & 0.5790 & 1.1561 & 1.2407 \\
& Voltage [V] & 0.0074 & 0.009 & 0.0085 & 0.0175 & 0.0161 \\
\hline \multirow{2}{*}{$R_{2}$ constant } & SOC [\%] & 0.3637 & 0.8782 & 0.6101 & 1.1755 & 1.1459 \\
& Voltage [V] & 0.0086 & 0.0089 & 0.0068 & 0.0169 & 0.00136 \\
\hline \multirow{2}{*}{$C_{2}$ constant } & SOC [\%] & 0.9623 & 0.8510 & 0.4341 & 1.1830 & 1.2193 \\
& Voltage [V] & 0.0077 & 0.0089 & 0.0054 & 0.0169 & 0.0153 \\
\hline
\end{tabular}

However, by comparing the results summarized in Tables 4 and 6, it can be concluded that generally, the differences between the two cases are rather small. This behavior suggests that the variation of the parameters of the EEC with the LTO-based Li-ion battery SOC has only a small impact on the accuracy of the SOC and voltage estimation.

The same conclusion can be drawn by comparing the maximum error values obtained for the two cases, which are summarized in Table 5 (parameters values changing with SOC) and Table 7 (parameters values constant with SOC). From Table 6, one can see that the SOC estimation error is below the acceptable error $(2 \%)$ in all the considered study cases. 

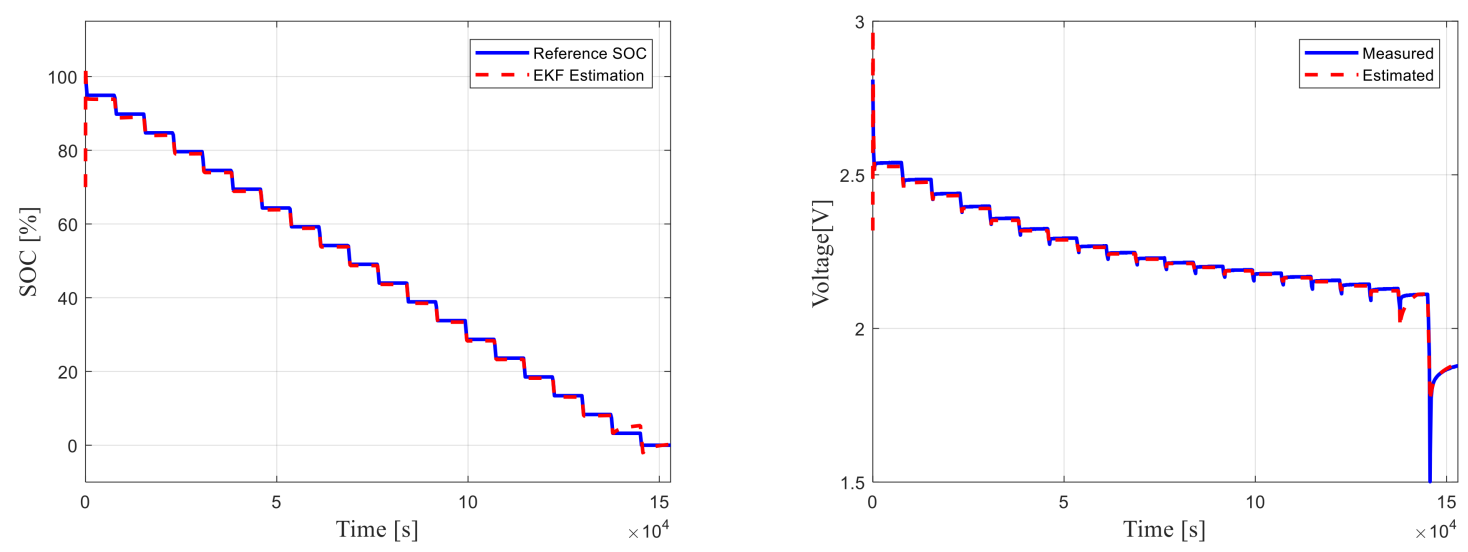

(a)
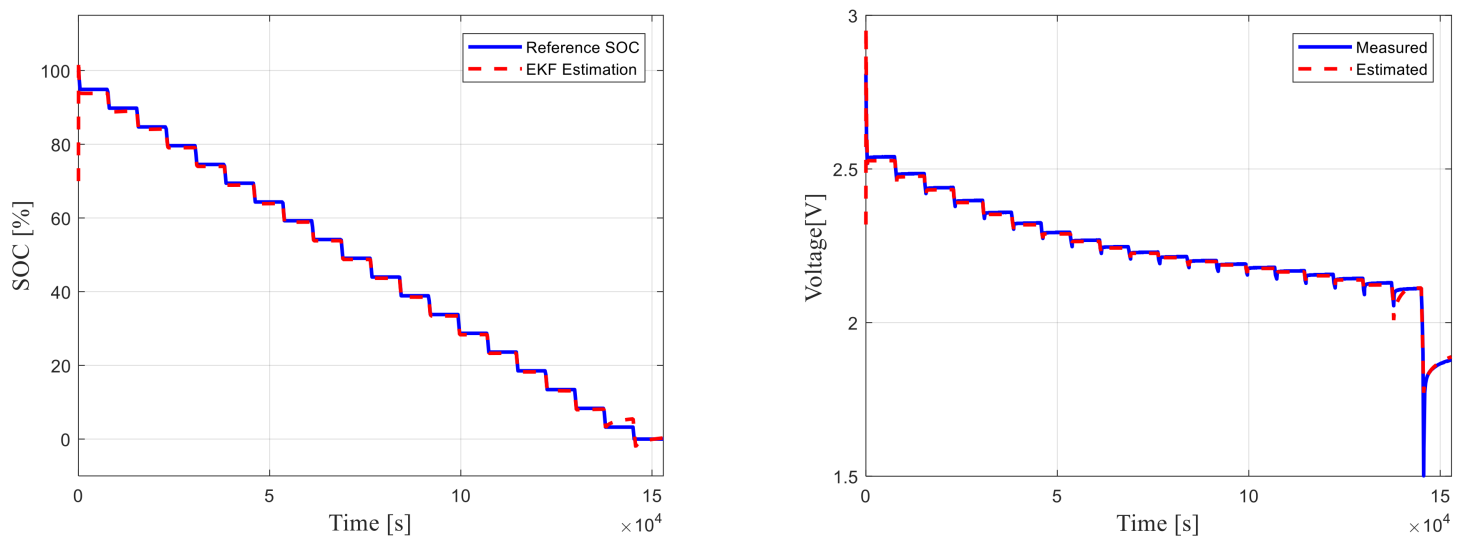

(b)
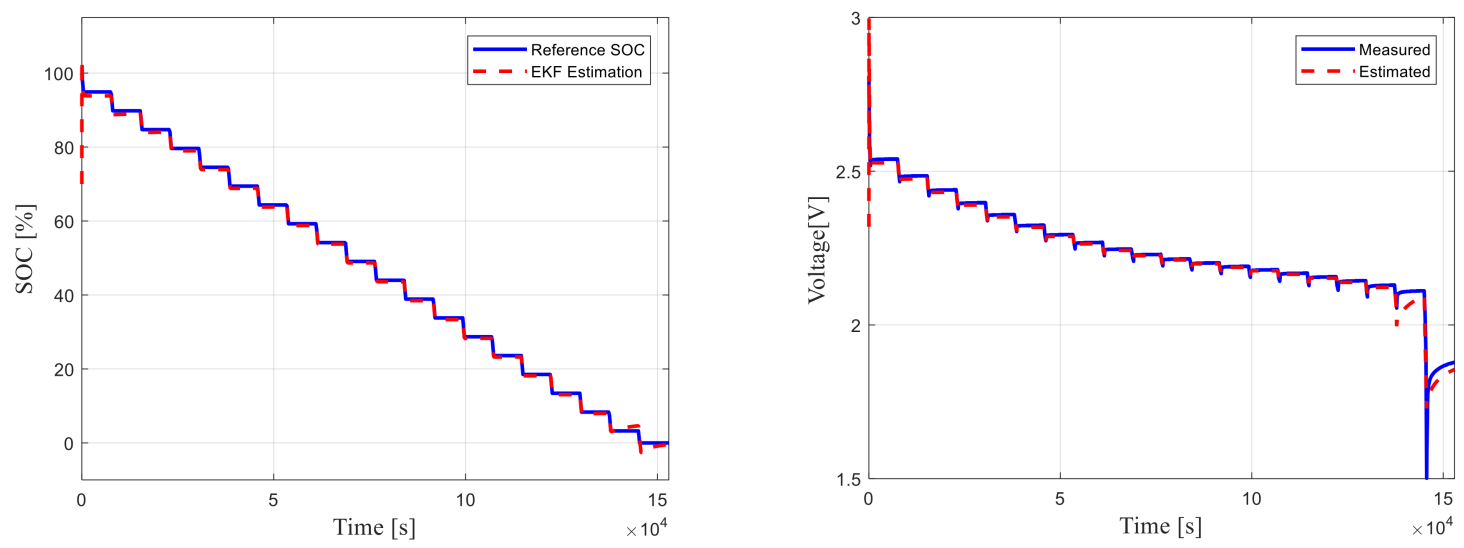

(c)

Figure 13. Cont. 

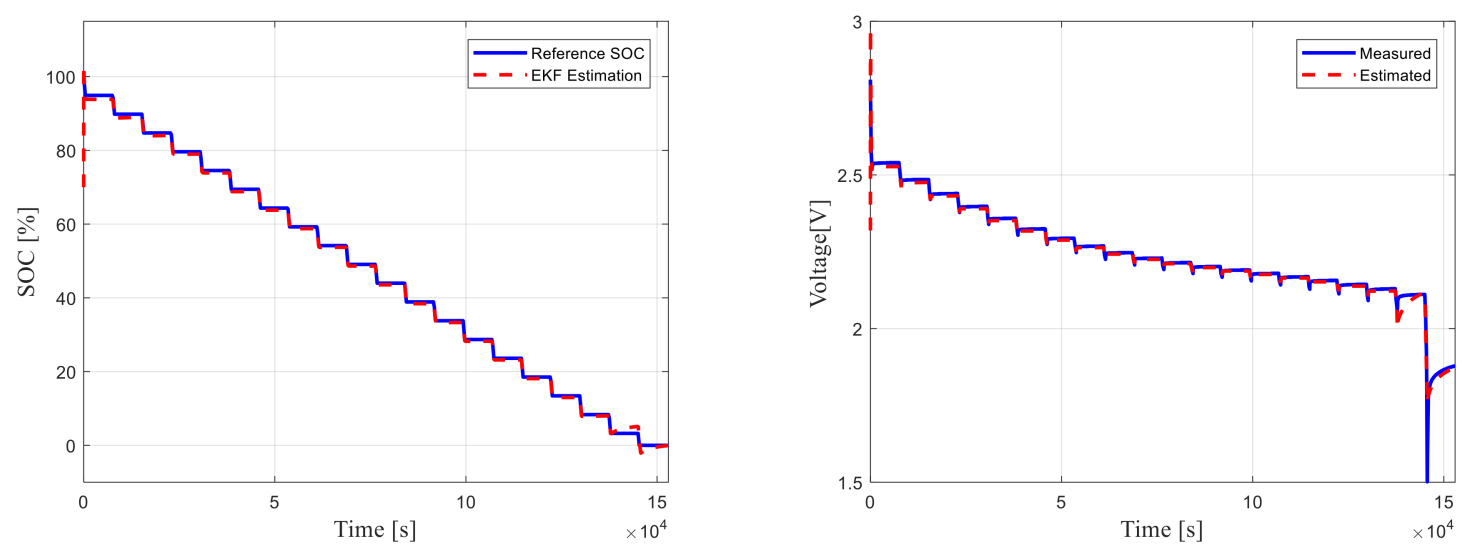

(d)
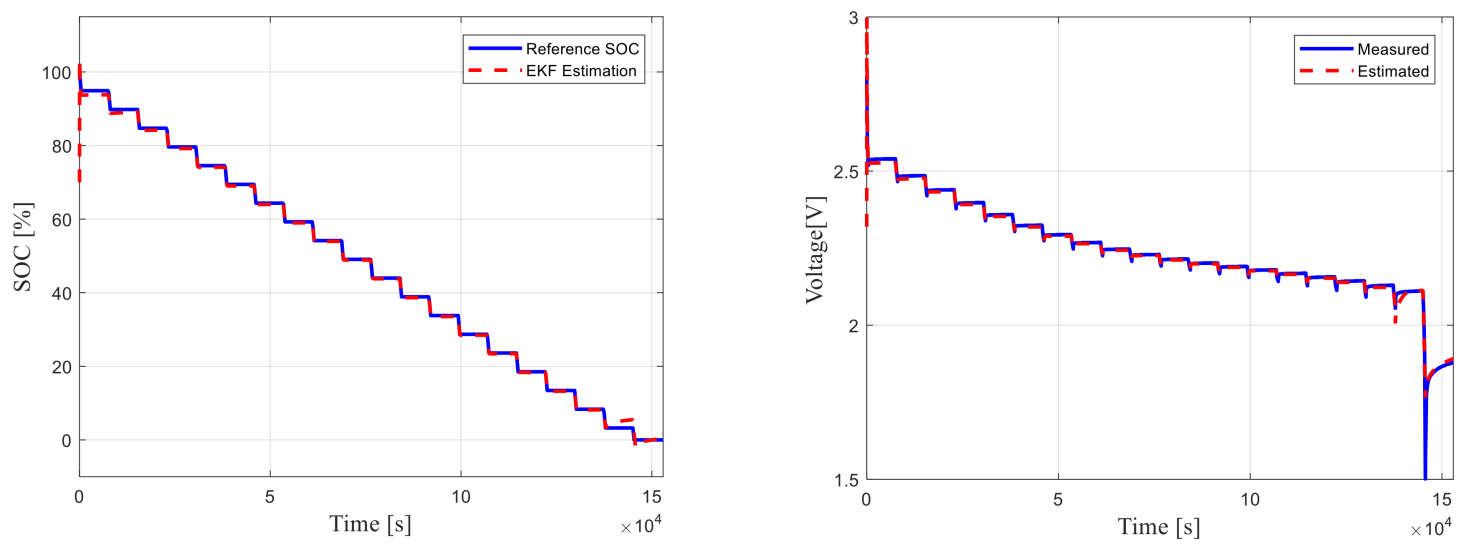

(e)

Figure 13. Comparison between the measured and estimation SOC (left) and voltage (right) profiles obtained during sensitivity analysis performed at $25^{\circ} \mathrm{C}$ for: (a) $R_{0}$ constant; (b) $R_{1}$ constant; (c) $C_{1}$ constant; (d) $R_{2}$ constant; (e) $C_{2}$ constant.

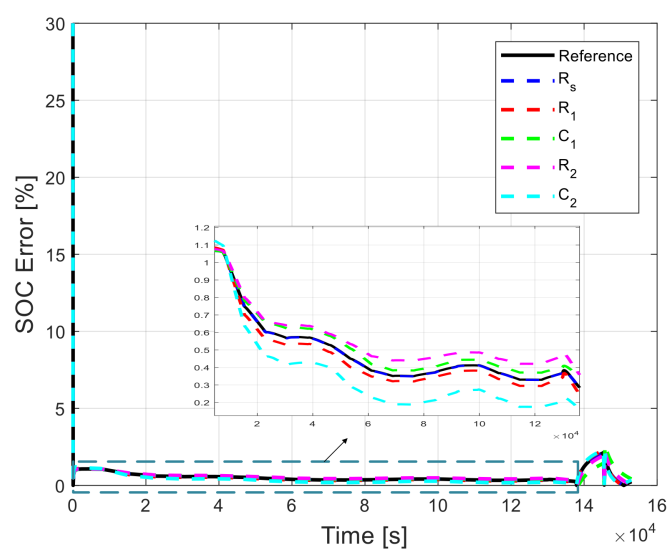

(a)

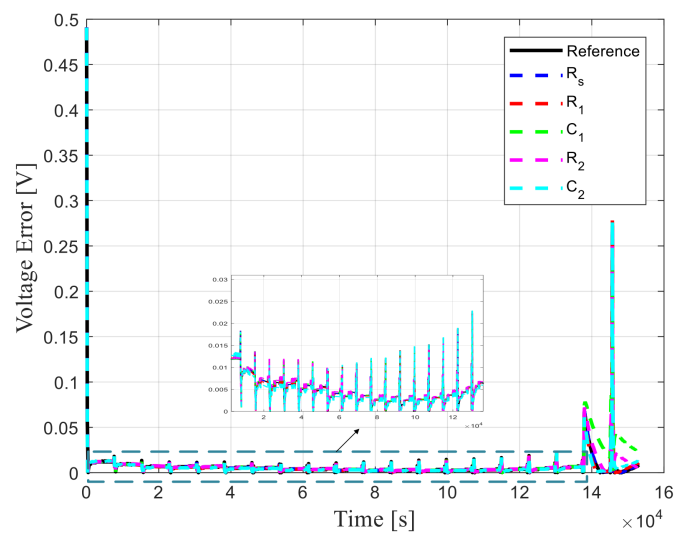

(b)

Figure 14. Estimation error curves at $25^{\circ} \mathrm{C}$ obtained during sensitivity analysis in terms of: (a) SOC; (b) Voltage. 
Table 7. Sensitivity analysis of the error of the SOC and battery voltage. Maximum error values (the shaded values represent the instances when the obtained errors, for the case when the average for the parameter was used, are higher than the errors for the case when the dependence on the SOC was considered).

\begin{tabular}{lcccccc}
\hline \multirow{2}{*}{ Condition } & Mean error & \multicolumn{5}{c}{ Temperature } \\
\cline { 3 - 7 } & & $\mathbf{5}{ }^{\circ} \mathbf{C}$ & $\mathbf{1 5}{ }^{\circ} \mathbf{C}$ & $\mathbf{2 5}{ }^{\circ} \mathbf{C}$ & $\mathbf{3 5}{ }^{\circ} \mathbf{C}$ & $\mathbf{4 5}{ }^{\circ} \mathbf{C}$ \\
\hline \multirow{2}{*}{$R_{o}$ constant } & SOC [\%] & 5.5756 & 1.7125 & 2.1296 & 3.3240 & 2.2414 \\
& Voltage [V] & 0.5597 & 0.0553 & 0.2716 & 0.1357 & 0.1225 \\
\hline \multirow{2}{*}{$R_{1}$ constant } & SOC [\%] & 5.7070 & 1.6713 & 2.284 & 3.2537 & 2.1477 \\
& Voltage [V] & 0.5613 & 0.0448 & 0.2781 & 0.1318 & 0.1126 \\
\hline \multirow{2}{*}{$C_{1}$ constant } & SOC [\%] & 5.6378 & 1.8295 & 2.6402 & 3.4126 & 2.4001 \\
& Voltage [V] & 0.5412 & 0.0580 & 0.2398 & 0.1407 & 0.1389 \\
\hline \multirow{2}{*}{$R_{2}$ constant } & SOC [\%] & 5.2382 & 1.7274 & 2.1197 & 3.2550 & 2.3199 \\
& Voltage [V] & 0.5613 & 0.0448 & 0.2781 & 0.1318 & 0.1126 \\
\hline \multirow{2}{*}{$C_{2}$ constant } & SOC [\%] & 6.5139 & 1.8620 & 2.2949 & 3.4093 & 2.2162 \\
& Voltage [V] & 0.5554 & 0.0584 & 0.2776 & 0.1406 & 0.1330 \\
\hline
\end{tabular}

Figure 14 illustrates the estimation errors obtained for SOC and battery voltage at $25^{\circ} \mathrm{C}$. As it can be observed, only at the beginning, there is a high error (30\%) due to the fact that initial SOC of the EKF method is set to $70 \%$. After estimated SOC converge to its reference, the estimated SOC stay close to the reference, overlapping with small errors in all the cases. From Figure 14a, it can be observed that $R_{2}$ and $C_{2}$ are the most sensitive parameters, and from Figure $14 \mathrm{~b}$ that $C_{2}$ is the most sensitive parameter. For example, keeping the parameter $C_{2}$ constant at its average value for the entire SOC interval will result in an increase in the voltage estimation error of about $10 \mathrm{mV}$ in comparison with the case when $C_{2}$ varies with SOC.

\section{Conclusions}

In this paper, a battery model-based on EKF SOC estimation algorithm was developed and verified for an LTO-based Li-ion battery. A second order RC-EEC was used to model the dynamics of the battery. The EEC was fully parameterized, based on extended laboratory measurements, by considering the variation of the circuit parameters with SOC, temperature, and C-rate. Furthermore, in order to estimate the battery SOC using the EKF method, a polynomial function has been used in order to map the VOC-SOC function and afterward used it for an optimal observer.

The proposed SOC estimation algorithm based on the EKF method is able to converge very fast, in a maximum of $100 \mathrm{~s}$, from the initial SOC used for initialization to the reference SOC that is based on Coulomb counting with known initial SOC. Accurate estimation results have been obtained when the SOC estimated by the developed model was compared with a reference SOC obtained using the Coulomb counting method for a step discharge profile; the mean absolute error varied between 0.444 to $1.1422 \%$, depending on the temperature, which is well below the $2 \%$ SOC estimation error mentioned in literature. Moreover, with the developed model it was also possible to predict accurately the battery voltage with a mean absolute error below $0.02 \mathrm{~V}$, independent of the considered temperature.

By performing a sensitivity analysis, it was shown that the SOC estimation is most sensitive to the variation with the SOC of the parameters of the two RC networks, while the voltage estimation is most sensitive to the change of capacitance $C_{1}$ with SOC; nevertheless, both SOC and voltage estimation are only slightly dependent on the changes of the EEC parameters with the SOC.

Acknowledgments: This work has been part of the "ALPBES: Advanced Lifetime Predictions of Battery Energy Storage" research project, which is financially supported by The Danish Council for Strategis Research.

Author Contributions: Ana-Irina Stroe performed the experiments, Jinhao Meng and Ana-Irina Stroe developed the models and wrote the paper; Daniel Stroe wrote the paper; Maciej Świerczyński, Remus Teodorescu and Søren Knudsen Kær reviewed the paper.

Conflicts of Interest: The authors declare no conflict of interest. 


\section{References}

1. Blomgren, G.E. The Development and Future of Lithium Ion Batteries. J. Electrochem. Soc. 2017, 164, A5019-A5025. [CrossRef]

2. Scrosati, B.; Garche, J. Lithium batteries: Status, prospects and future. J. Power Sources 2010, 195, 2419-2430. [CrossRef]

3. Stroe, D.-I.; Stan, A.-I.; Diosi, R.; Teodorescu, R.; Andreasen, S.J. Short term energy storage for grid support in wind power applications. In Proceedings of the 13th International Conference on Optimization of Electrical and Electronics Equipment (OPTIM), Brasov, Romania, 24-26 May 2012; pp. 1012-1021.

4. Stan, A.-I.; Swierczynski, M.; Stroe, D.-I.; Teodorescu, R.; Andreasen, S.J. Lithium Ion Battery Chemistries from Renewables Energy Storage to Automotive and Back-up Power Applications-An Overview. In Proceedings of the 14th International Conference on Optimization of Electrical and Electronics Equipment (OPTIM), Brasov, Romania, 22-24 May 2014; pp. 713-720.

5. Chemali, E.; Preindl, M.; Malusz, P.; Emadi, A. Electrochemical and Electrostatic Energy Storage and Management Systems for Electric Drive Vehicles: State-of-the-Art Review and Future Trends. IEEE J. Emerg. Sel. Top. Power Electron. 2015, 4, 1117-1134. [CrossRef]

6. Goodenough, J.B.; Park, K.-S. The Li-Ion Rechargeable Battery: A Perspective. J. Am. Chem. Soc. 2013, 135, 1167-1176. [CrossRef] [PubMed]

7. Meng, J.; Ricco, M.; Luo, G.; Swierczynski, M.; Stroe, D.-I.; Stroe, A.-I.; Teodorescu, R. An Overview and Comparison of Online Implementable SOC Estimation Methods for Lithium-ion Battery. IEEE Trans. Ind. Appl. 2017, 54, 1583-1591. [CrossRef]

8. Chaoui, H.; Golbon, N.; Hmouz, I.; Souissi, R.; Tahar, S. Lyapunov-Based Adaptive State of Charge and State of Health Estimation for Lithium-Ion Batteries. IEEE Trans. Ind. Electron. 2015, 62, 1610-1618. [CrossRef]

9. Xu, B.; Cao, Z.; Chen, Z.; Zou, Z. An online state of charge estimation method with reduced prior battery testing information. Int. J. Electr. Power Energy Syst. 2014, 63, 178-184. [CrossRef]

10. Jeong, Y.M.; Cho, Y.K.; Ahn, J.H.; Ryu, S.H.; Lee, B.K. Enhanced Coulomb counting method with adaptive SOC reset time for estimating OCV. In Proceedings of the IEEE Energy Conversion Congress and Exposition (ECCE), Pittsburgh, PA, USA, 14-18 September 2014; pp. 1313-1318. [CrossRef]

11. Waag, W.; Sauer, D.U. Adaptive estimation of the electromotive force of the lithium-ion battery after current interruption for an accurate state-of-charge and capacity determination. Appl. Energy 2013, 111, 416-427. [CrossRef]

12. Zhu, L.; Sun, Z.; Dai, H.; Wei, X. A novel modeling methodology of open circuit voltage hysteresis for LiFePO4 batteries based on an adaptive discrete Preisach model. Appl. Energy 2015, 155, 91-109. [CrossRef]

13. Wei, Z.; Zou, C.; Leng, F.; Hee Soong, B.; Tseng, K.J. Online Model Identification and State-of Charge Estimate for Lithium-Ion Battery With a Recursive Total Least Squares-Based observer. IEEE Trans. Ind. Electron. 2018, 65, 1336-1346. [CrossRef]

14. Meng, J.; Luo, G.; Gao, F. Lithium Polymer Battery State-of-Charge Estimation Based on Adaptive Unscented Kalman Filter and Support Vector Machine. IEEE Trans. Power Electron. 2016, 31, 2226-2238. [CrossRef]

15. Luo, G.; Meng, J.; Ji, X.; Cai, X.; Gao, F. A data driven model for accurate SOC estimation in EVs. In'Proceedings of the IEEE International Conference on Industrial Technology (ICIT), Toronto, ON, Canada, 22-25 March 2017; pp. 352-357.

16. He, H.; Xiong, R.; Zhang, X.; Sun, F.; Fan, J. State-of-Charge Estimation of the Lithium-Ion Battery Using an Adaptive Extended Kalman Filter Based on an Improved Thevenin Model. IEEE Trans. Veh. Technol. 2011, 60, 1461-1469. [CrossRef]

17. Chen, Z.; Fu, Y.; Mi, C.C. State of Charge Estimation of Lithium-Ion Batteries in Electric Drive Vehicles Using Extended Kalman Filtering. IEEE Trans. Veh. Technol. 2013, 62, 1020-1030. [CrossRef]

18. He, H.; Qin, H.; Shui, Y.; Oleksandr, K. Lithium-Ion Battery SOC Estimation with UKF and RTOS $\mu$ COS-II Platform. Energy Procedia 2014, 61, 468-471. [CrossRef]

19. Yu, Q.; Xiong, R.; Lin, C.; Shen, W.; Deng, J. Lithium-Ion Battery Parameters and State-of-Charge Joint Estimation Based on H-Infinity and Unscented Kalman Filters. IEEE Trans. Veh. Technol. 2017, 66, 8693-8701. [CrossRef] 
20. He, F.; Shen, W.X.; Kapoor, A.; Honnery, D.; Dayawansa, D. H infinity observer based state of charge estimation for battery packs in electric vehicles. In Proceedings of the IEEE 11th Conference on Industrial Electronics and Applications (ICIEA), Hefei, China, 5-7 June 2016; pp. 694-699.

21. Xu, J.; Mi, C.C.; Cao, B.; Deng, J.; Chen, Z.; Li, S. The State of Charge Estimation of Lithium-Ion Batteries Based on a Proportional-Integral Observer. IEEE Trans. Veh. Technol. 2014, 63, 1614-1621. [CrossRef]

22. Zhou, D.; Zhang, K.; Ravey, A.; Gao, F.; Miraoui, A. On-line estimation of lithium polymer batteries state-of-charge using particle filter based data fusion with multi-models approach. IEEE Trans. Ind. Appl. 2016, 52, 2582-2595. [CrossRef]

23. Wei, Z.; Lim, T.M.; Skyllas-Kazacos, M.; Wai, N.; Tseng, K.J. Online state of charge and model parameter co-estimation based on a novel multi-timescale estimator for vanadium redox flow battery. Appl. Energy 2016, 172, 169-179. [CrossRef]

24. Wei, Z.; Meng, S.; Xiong, B.; Ji, D.; Tseng, K.J. Enhanced online model identification and state of charge estimation for lithium-ion battery with a FBCRLS based observer. Appl. Energy 2016, 181, 332-341. [CrossRef]

25. Zhang, C.; Li, K.; Mcloone, S.; Yang, Z. Battery modelling methods for electric vehicles-A review. In Proceedings of the 2014 European Control Conference (ECC), Strasbourg, France, 24-27 June 2014; pp. 2673-2678.

26. Rahimidi-Eichi, H.; Baronti, F.; Chow, M.-Y. Modelling and online parameter identification of Li-Polymer battery cells for SOC estimation. In Proceedings of the IEEE International Symposium on Industrial Electronics (ISIE), Hangzhou, China, 28-31 May 2012; pp. 1336-1341.

27. Zou, C.; Hu, X.; Wei, Z.; Wik, T.; Egardt, E. Electrochemical Estimation and Control for Lithium-Ion Battery Health-Aware Fast Charging. IEEE Trans. Ind. Electr. 2017, 99, 1-11. [CrossRef]

28. Stroe, D.-I.; Swierczynski, M.; Stroe, A.I.; Kær, S.K. Generalized Characterization Methodology for Performance Modelling of Lithium-Ion Batteries. Batteries 2016, 2, 37. [CrossRef]

29. Grandjean, T.R.; McGordon, A.; Jennings, P.A. Structural Identifiability of Equivalent Circuit Models for Li-Ion Batteries. Energies 2017, 10, 90. [CrossRef]

30. Cheng, X.; Yao, L.; Xing, Y.; Pecht, M. Novel Parametric Circuit Modeling for Li-Ion Batteries. Energies 2016, 9, 539. [CrossRef]

31. Rahini-Eichi, H.; Balagopal, B.; Chow, M.; Yeo, T.J. Sensitivity Analysis of Lithium-Ion Battery Model to Battery Parameters. In Proceedings of the IECON 39th Annual Conference of the IEEE Industrial Electronics Society, Vienna, Austria, 10-13 November 2013; pp. 6794-6799.

32. Zhao, S.; Howey, D.A. Global sensitivity analysis of battery equivalent circuit model parameters. In Proceedings of the IEEE Vehicle Power and Propulsion Conference (VPPC), Hangzhou, China, 17-20 October 2016.

33. He, H.; Xiong, R.; Fan, J. Evaluation of Lithium-Ion Battery Equivalent Circuit Models for State of Charge Estimation by an Experimental Approach. Energies 2011, 4, 582-598. [CrossRef]

34. Li, J.; Mazzola, M.S. Accurate battery pack modeling for automotive applications. J. Power Sources 2013, 237, 215-228. [CrossRef]

35. Rahimidi-Eichi, H.; Baronti, F.; Chow, M.-Y. Online Adaptive Parameter Identification and State-of-Charge Coestimation for Lithium-Polymer Battery Cells. IEEE Trans. Ind. Electron. 2014, 61, 2053-2061. [CrossRef]

36. Malysz, P.; Ye, J.; Gu, R.; Yang, H.; Emadi, A. Battery State-of-Power Peak Current Calculation and Verification Using an Asymmetric Parameter Equivalent Circuit Model. IEEE Trans. Veh. Technol. 2016, 65, 4512-4522. [CrossRef]

37. Hentunen, A.; Lehmuspelto, T.; Suomela, J. Time-Domain Parameter Extraction Method for Thevenin-Equivalent Circuit Battery Models. IEEE Trans. Energy Convers. 2014, 29, 558-566. [CrossRef]

38. Li, X.; Jiuchun, J.; Zhang, C.; Wang, L.Y.; Zheng, L. Robustness of SOC Estimation Algorithm for EV Lithium-Ion Batteries against Modeling Errors and Measurement Noise. Math. Probl. Eng. 2015, 2015. [CrossRef]

(C) 2018 by the authors. Licensee MDPI, Basel, Switzerland. This article is an open access article distributed under the terms and conditions of the Creative Commons Attribution (CC BY) license (http:/ / creativecommons.org/licenses/by/4.0/). 